\title{
Migrações e urbanização em Santa Catarina
}

Juliano Giassi Goularti ${ }^{1}$

\section{RESUMO}

O objetivo deste trabalho é discutir as migrações no Estado de Santa Catarina no período das últimas décadas. Com base nos dados disponibilizados pelo Censo/IBGE (1940-2010), é possível relacionar o aumento das migrações com o processo de urbanização e o surgimento da problemática urbana, como por exemplo, a violência. Pelos dados, verifica-se que as cidades que apresentam um maior grau de complexidade industrial como Joinville, Blumenau, Florianópolis, Itajaí, Chapecó e seu hinterland são as mais procuradas pelos migrantes e as que mais tiveram crescimento de sua população muito acima da média estadual. Por outro lado, as cidades com menor grau de desenvolvimento perderam população residente. Embora Santa Catarina não possuam grandes metrópoles a exemplo de São Paulo, Rio de Janeiro, Salvador, Brasília, Recife, etc., o não está inerente ao chamado caos urbano.

Palavras chaves: Migrações, Urbanização, Santa Catarina.

\section{Migration and urbanization in Santa Catarina}

\begin{abstract}
The objective of this paper is to discuss migration in the state of Santa Catarina in the period in decades. Based on data provided by the census, it is possible to relate the increased migration to the process of urbanization and the emergence of urban issues, such as violence. From the data, it turns out that the cities that have a higher degree of complexity as industrial Joinville, Blumenau, Florianópolis, Itajaí, Chapecó and its hinterland are the most sought after by migrants and that most of its population grew well above the state average. On the other hand, cities with less developed lost residents. Although Santa Catarina is not a major metropolis example of São Paulo, Rio de Janeiro, Salvador, Brasília, Recife, etc., the state is not inherent in the so called urban chaos.
\end{abstract}

Key words: Migration, Urbanization, Santa Catarina.

\begin{abstract}
As cidades são como transformadores elétricos: aumentam as tensões, precipitam as trocas, caldeiam constantemente a vida dos homens. (...) Todos os grandes momentos do crescimento se exprimem por uma explosão urbana (BRAUDEL, 1995, p. 439).
\end{abstract}

\section{INTRODUÇÃO}

Trabalhando com os dados disponibilizados pelo Censo/IBGE (1940-2010), o objetivo deste trabalho é analisar a mobilidade espacial em Santa Catarina na segunda metade do século XX e na primeira década do século XXI. Dentro do processo histórico da mobilidade

\footnotetext{
1 Economista, Mestre em Desenvolvimento Regional. Doutorando em Desenvolvimento Econômico pela UNICAMP. Membro da Associação de Pesquisadores em Economia (APEC) e do Centro de Estudos de Desenvolvimento Econômico (IE-UNICAMP). E-mail: jggoularti@gmail.com
} 
espacial da população, em especial, a migração interna, é um fenômeno estrutural que segue o a dinâmica da industrialização, a estrutura fundiária, o desenvolvimento do mercado interno e a possibilidade por melhores condições de vida. Deste modo, o que foi de certa forma suportável até meados de 1980, à medida que avançou a década, mudou as características das cidades mudando a problemática urbana, passando rapidamente ao caos.

As transformações econômicas coordenadas pelo Estado em sua forma superior de organização capitalista a partir de 1960 imprimem uma nova dinâmica, rural é urbana. Neste particular, a cidade como um "transformador elétrico" (BRAUDEL, 1995) que transmiti energia de um circuito a outro, induzindo tensões/correntes modificando o um circuito elétrico, passam a concentrar a maior parte da população. Com o crescimento econômico e o processo de “industrialização pesada" (CARDOSO DE MELLO, 1998), a integração física territorial associada ao crescimento do mercado, cidades como Joinville, Blumenau, Florianópolis e seu hinterland cresceram muito acima da média estadual. Embora a conurbação urbana e o número de habitantes em Santa Catarina serem proporcionalmente inferiores as conurbações das grandes cidades brasileira, a violência, a pobreza urbana e a autoconstrução de moradias em morros, encosta de morros e áreas de riscos também ocorrem no Estado.

A economia catarinense torna-se, fundamentalmente, urbana e industrial e se expandem em direção ao Litoral. Demonstrações de dados do Censo/IBGE (1970-2010) revelam que as cidades como Joinville, Florianópolis, Blumenau que apresentam um maior grau de complexidade na divisão social do trabalho cresceram um pouco acima da média aritmética das demais cidades catarinenses. Estas três cidades que em 1970 representavam, sucessivamente, $4,34 \%, 4,77$ e $3,46 \%$ da população catarinense passaram para $8,34 \%, 6,82 \%$ e 5,00\% em 2010 enquanto que no mesmo período cidades como Lages, Tubarão, e Concórdia que representavam 4,44\%, 2,30\% e 1,57\% da população de Santa Catarina em 1970 passaram a representar 2,54\%, 1,57\% e 1,11\% em 2010.

Quanto à questão dos fluxos migratórios para cidades, esta supostamente como agente civilizador, até os fins da década de 1970 era uma esperança de uma vida melhor, pós 1980 era uma forma de sobrevivência (CANO, 2008). Entretanto é preciso entender que as migrações partem de nossa heterogeneidade estrutural obedecendo às especificidades do desenvolvimento econômico, da estrutura fundiária e da metamorfose da sociedade.

O Estado relegando a segundo plano o planejamento especificamente urbano, permitiu que a urbanização se desse de forma desorganizada, resultando o que hoje denominamos de 
"caos urbano". Para tanto, este novo perfil da sociedade catarinense carrega consigo traços da violência e desequilíbrios regionais e sociais. Sem considerar a perversa especulação imobiliária que é extremamente prejudicial para as cidades, que tem como finalidade a segregação sócio espacial conservando os lotes centrais e nobres valorizando o seu custo e exportando os pobres para bairros periféricos.

\section{2 (DES)RURALIZAÇÃO DO MEIO RURAL}

Ao contrário do Brasil, onde o padrão de ocupação rural ao longo de vários séculos foi extensivo (baseado em grandes extensões de terras), em função de sua condição colonial e, mais tarde, de país primário exportador, em Santa Catarina foi constituído na pequena propriedade. A partir de meados do século XX, em sintonia com o crescimento da produção industrial e ampliação do mercado nacional, as cidades catarinenses começam a se expandir. O grande salto ocorreu com o desenvolvimento da infraestrutura, especialmente transportes e energia elétrica, a partir do PLAMEG durante a administração de Celso Ramos (1961-1965). Desta forma, houve uma reconfiguração da rede urbana, determinando uma nova geografia econômica e regional. Neste período, $50,41 \%$ da estrutura da renda interna era oriunda da agricultura, enquanto que $20,72 \%$ da indústria e $28,91 \%$ do setor de serviços, e $68,18 \%$ da população viviam no meio rural.

A integração físico-territorial e a formação do sistema nacional de economia de mercado têm como base a infraestrutura, especialmente transportes, energia e telecomunicações. Os traçados das novas vias de transporte (ferrovias, rodovias, vias de navegação, linhas aéreas) tiveram impactos decisivos sobre o sentido dos fluxos e sobre a integração da economia e da sociedade brasileiras. A partir dos investimentos coordenados pelo Estado durante a execução do PLAMEG (1961-1965), PLAMEG II (1966-1970) e do Projeto Catarinense de Desenvolvimento (1971-1974), em sintonia com o crescimento da produção industrial e ampliação do mercado nacional, as cidades catarinenses na faixa litorânea se expandem (DINIZ, 2005).

Entre os anos de 1960 e 2010 as principais determinações do processo de urbanização em Santa Catarina decorreram basicamente da industrialização, da precarização das relações sociais (serviços públicos e privados) no campo, da especialização produtiva e das políticas de desenvolvimento regional desigual fomentado pelo Estado. Por intermédio da política de planejamento eminentemente econômico dos anos 1960 e 1970, produziu-se um conjunto de alterações sobre os determinantes que agem sobre os processos de migração da zona rural 
para o meio urbano. A indústria e o comércio sendo uma atividade urbana, ao crescerem sua participação no conjunto da riqueza estadual, da se início o processo de migração para cidades.

Muito embora Santa Catarina tenha tido um processo transitório de urbanização em ritmo mais lento, por se constituir uma economia de pequenas propriedades rurais, formação industrial constituída com base na pequena e média empresa familiar e por apresentar uma maior equidade da distribuição da propriedade e da renda, lembramos que a divisão social do trabalho também abrange o Estado e por isso sua economia e sociedade não estão imunes as contradições capitalistas.

Embora o espaço "urbano e o rural nunca se separam como azeite da água: há simultaneamente separação e aproximação, divisão e reagrupamento" (BRAUDEL, 1995, p. 446), a taxa de urbanização no Estado passou de 21,32\% em 1940 para 59,41\% em 1980 e 83,90\% em 2010 IBGE (2011). Diríamos, de outra forma, se por um lado houve planejamento estatal para expansão da atividade industrial, por outro houve omissão do planejamento especificamente urbano. A interação entre planejamento econômico e planejamento especificamente urbano não se desenvolveu plenamente, assim, o agravamento dos problemas urbanos é inexorável. A síntese da urbanização de Santa Catarina - na América Latina e Brasil - é o descaso com os serviços públicos de educação e saúde, transporte coletivo, mobilidade, saneamento básico, violência e moradia resultaram numa grave deterioração do padrão de vida urbana.

Ao contrário dos países europeus em que a urbanização se deu de forma lenta, no caso brasileiro a urbanização se deu num ritmo acelerado. Se nos países europeus o processo de industrialização foi capaz de absorver parte considerável do êxodo rural, no caso brasileiro a nossa industrial periférica demonstrou-se incapaz de absorver o excedente demográfico (CANO, 2011). Num período de 50 anos (1950-2000) o grau de urbanização subiu do patamar de $36,16 \%$ para $85,10 \%$. Assim a urbanização acabou gerando uma exclusão urbanística, ou como sugerida por Cano (2008) uma "arrebentação urbana", representada pela gigantesca ocupação ilegal do solo urbano que é ignorada na representação da cidade oficial.

Ligado ao desenvolvimento da economia de mercado, a ausência de serviços públicos e privados no meio rural, o fenômeno passa pela criação de novas indústrias-serviços que por sua vez faz aumentar consideravelmente a procura de empregos nas cidades que já apresentam um maior grau de desenvolvimento e de complexidade industrial e também comercial. 
Tabela 1: População residente, por situação do domicílio em Santa Catarina, 1940 e 2010

\begin{tabular}{c|c|c|c|c|c}
\hline ANOS & Total & Urbana & (\% Total) & Rural & (\% Total) \\
\hline 1940 & 1.178 .340 & 253.717 & 21,53 & 924.623 & 78,47 \\
\hline 1950 & 1.560 .502 & 362.717 & 23,24 & 1.197 .785 & 76,76 \\
\hline 1960 & 2.118 .116 & 673.981 & 31,82 & 1.444 .135 & 68,18 \\
\hline 1970 & 2.901 .734 & 1.246 .043 & 42,94 & 1.655 .691 & 57,06 \\
\hline 1980 & 3.627 .933 & 2.154 .238 & 59,38 & 1.473 .695 & 40,62 \\
\hline 1991 & 4.541 .994 & 3.208 .537 & 70,64 & 1.333 .457 & 29,36 \\
\hline 2000 & 5.356 .360 & 4.217 .931 & 78,75 & 1.138 .429 & 21,25 \\
\hline 2010 & 6.248 .436 & 5.247 .913 & 83,99 & 1.000 .523 & 16,01 \\
\hline
\end{tabular}

Fonte: IBGE, vários anos.

Em Santa Catarina, nos últimos 70 anos a população mais que quintuplicou, subindo de 1.178 milhões de habitantes em 1940 para 6.248 milhões em 2010 e a previsão do IBGE é de que o Estado alcance 7 milhões de habitantes em 2017 e 8 milhões em 2030. Enquanto que os municípios que mais cresceram nas últimas décadas situam próximos à faixa litorânea, os que mais sofreram perdas populacionais situam na região Oeste e Meio-Oeste. Registra-se também que entre 1970 e 2010 houve pouca alteração na lista dos dez maiores municípios. O ponto a ser levantado é que na década de 1970 os dez maiores municípios representavam 29,12\% da população catarinense e em 2010 passaram a concentrar 39,70\%, um crescimento de 36,53\%. Os fluxos regionais migratórios transformaram cidades como Joinville, Florianópolis, Blumenau, Chapecó é Itajaí em "transformadores elétricos" (BRAUDEL, 1995), maior receptor estadual, ampliando ainda mais sua urbanização.

\section{FLUXOS MIGRATÓRIOS E URBANIZAÇÃO}

O resultado desse processo de urbanização está se refletindo na crise urbana, embora a urbanização seja inevitável, não foi por falta de planejamento, planos e legislações urbanísticas que as cidades cresceram e estão crescendo de forma desordenada (MARICATO, 2000). A problemática é que o planejamento especificamente urbano foi relegado. A velocidade e o adensamento urbano - notadamente em Joinville, Florianópolis, Blumenau, São José e Criciúma - amplificaram as tensões sociais, desencadeando, no plano político, uma crescente massa de reivindicações com fortes conteúdos de justiça social derivado da segregação e exclusão social. 
Tabela 2: População das dez maiores cidades catarinenses, 1970 e 2010

\begin{tabular}{l|c|c|c|c|c|c}
\hline Municípios & Censo 1970 & Censo 1980 & Censo 1991 & Censo 2000 & Censo 2010 & $\begin{array}{c}\text { Crescimento } \\
\mathbf{1 9 7 0 - 2 0 1 0}\end{array}$ \\
\hline Santa Catarina & 2.901 .660 & 3.628 .292 & 4.541 .994 & 5.356 .360 & 6.248 .436 & 112,93 \\
\hline Florianópolis & 138.337 & 187.880 & 255.390 & 342.315 & 421.240 & 204,50 \\
\hline Lages & 128.728 & 155.295 & 151.235 & 157.682 & 156.727 & 21,75 \\
\hline Joinville & 126.058 & 235.803 & 347.151 & 429.604 & 515.288 & 308,77 \\
\hline Blumenau & 100.275 & 157.251 & 212.025 & 261.808 & 309.011 & 208,16 \\
\hline Criciúma & 81.452 & 110.597 & 146.320 & 170.420 & 192.308 & 136,10 \\
\hline Tubarão & 66.876 & 75.242 & 95.062 & 88.470 & 97.235 & 45,40 \\
\hline Itajaí & 63.139 & 86.456 & 119.631 & 147.494 & 183.373 & 190,43 \\
\hline Chapecó & 49.865 & 83.772 & 123.050 & 146.967 & 183.530 & 268,05 \\
\hline Concórdia & 45.465 & 59.426 & 64.338 & 63.058 & 68.621 & 50,93 \\
\hline
\end{tabular}

Fonte: IBGE, vários anos.

A demonstração dos dados revela que as cidades como Joinville, Florianópolis, Blumenau que apresentam um maior grau de complexidade industrial cresceram acima da média estadual e do crescimento dos municípios com menor grau de complexidade industrial. Estas três cidades que em 1970 representavam, sucessivamente, 4,34\%, 4,77\% e 3,46\% da população catarinense passaram para $8,34 \%, 6,82 \%$ e 5,00\% em 2010. No período destaca o crescimento populacional abaixo da média de Lages, Tubarão e Concórdia. Estes municípios que em 1970 representavam 4,44\%, 2,30\% e 1,57\% da população de Santa Catarina passaram a representar 2,54\%, 1,57\% e 1,11\% em 2010. No geral, Joinville, Florianópolis, Blumenau que representavam $12,57 \%$ da população estadual em 1970 passaram a representar 20,16\% em 2010. Enquanto que Lages, Tubarão, e Concórdia passaram de 8,31\% para 5,22\%.

Tabela 3: Participação dos dez maiores municípios na população catarinenses, 1970 e 2010

\begin{tabular}{l|c|c|c|c|c|c}
\hline \multicolumn{1}{c|}{ Municípios } & $\begin{array}{c}\text { Censo } \\
\mathbf{1 9 7 0}\end{array}$ & $\begin{array}{c}\text { Censo } \\
\mathbf{1 9 8 0}\end{array}$ & $\begin{array}{c}\text { Censo } \\
\mathbf{1 9 9 1}\end{array}$ & $\begin{array}{c}\text { Censo } \\
\mathbf{2 0 0 0}\end{array}$ & $\begin{array}{c}\text { Censo } \\
\mathbf{2 0 1 0}\end{array}$ & $\begin{array}{c}\text { Crescimento } \\
\mathbf{1 9 7 0 - 2 0 1 0}\end{array}$ \\
\hline Florianópolis & 4,77 & 5,18 & 5,62 & 6,39 & 6,82 & 43,00 \\
\hline Lages & 4,44 & 4,28 & 3,33 & 2,94 & 2,54 & $-42,82$ \\
\hline Joinville & 4,34 & 6,50 & 7,64 & 8,02 & 8,34 & 91,97 \\
\hline Blumenau & 3,46 & 4,33 & 4,67 & 4,89 & 5,00 & 44,72 \\
\hline Criciúma & 2,81 & 3,05 & 3,22 & 3,18 & 3,11 & 10,88 \\
\hline Tubarão & 2,30 & 2,07 & 2,09 & 1,65 & 1,57 & $-31,72$ \\
\hline Itajaí & 2,18 & 2,38 & 2,63 & 2,75 & 2,97 & 36,39 \\
\hline Chapecó & 1,72 & 2,31 & 2,71 & 2,74 & 2,97 & 72,85 \\
\hline Concórdia & 1,57 & 1,64 & 1,42 & 1,18 & 1,11 & $-29,12$ \\
\hline
\end{tabular}

Fonte: IBGE, vários anos. 
Dados do Censo 2010 revelam ainda que dos 25 maiores municípios apenas Lages teve perda de população residente. Observa-se também que decorrido do processo de migração o conjunto dos municípios compreendidos pelas Secretarias de Desenvolvimento Regional (SDR) de Quilombo sofreram uma perda populacional de 7,31\%, Lages 2,10\%, São Lourenço do Oeste 0,90\%, Seara 0,82\% e Dionísio Cerqueira 0,64\%. O Censo 2010 revela que em 23 de 36 regiões o município sede cresceu mais que a média dos restantes dos municípios, e em 13 o município sede cresceu menos (IBGE, 2011). Neste particular, a descentralização administrativa e política do Estado foi, portanto, em grande medida, uma política de não enfrentamento da problemática urbana. Não por menos, passados mais de uma década, que podemos atribuir que a política de descentralização em Santa Catarina é um mito (GOULARTI, 2014b).

Mapa 1: Taxa de Crescimento Populacional por SDR, 2000 e 2010

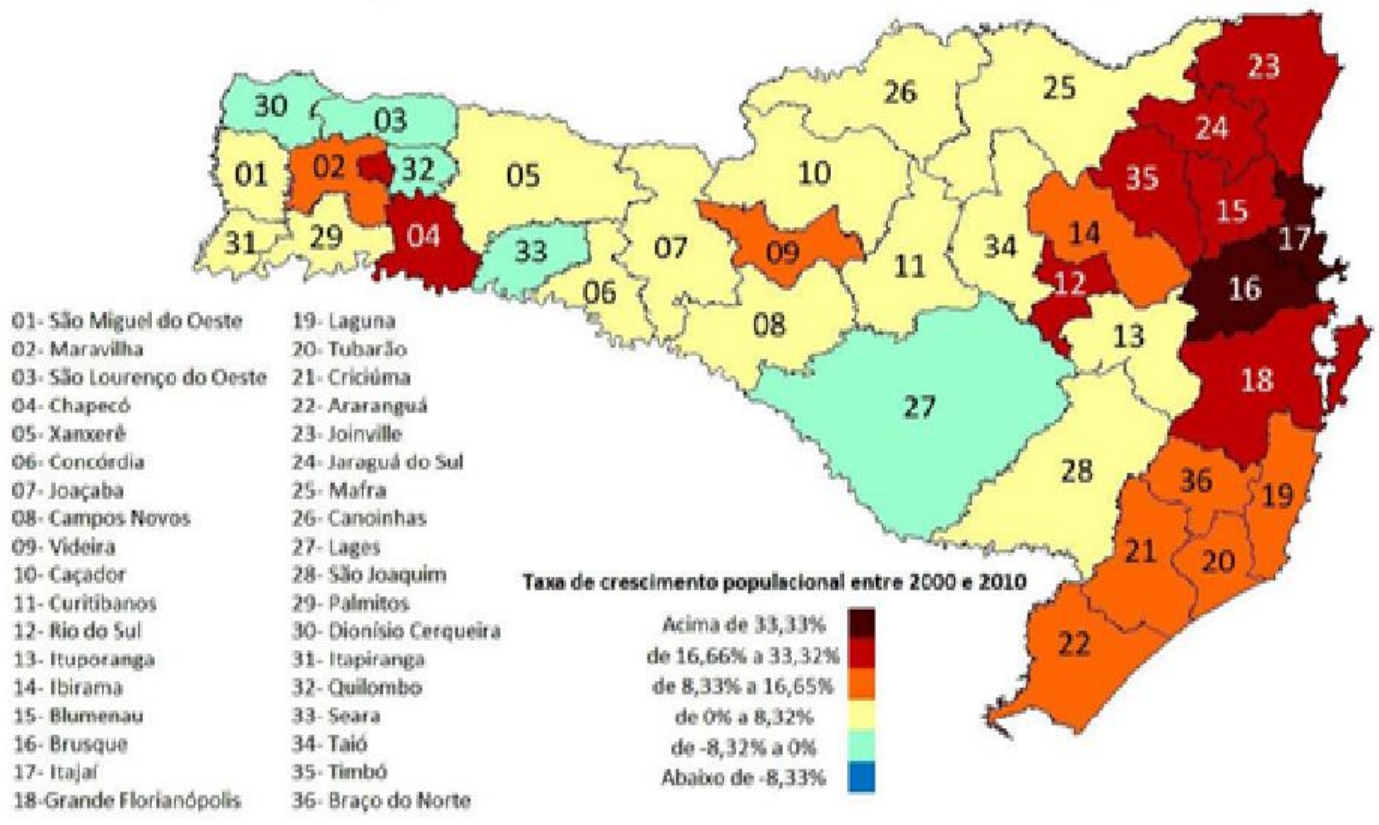

Fonte: IBGE, 2011.

Com resultado da criação de novos municípios, nos últimos 20 anos (1990-2010), o número de municípios com população entre 1 e 3.000 mil habitantes cresceu de nove para 55 . Dos 76 novos municípios criados no período, 47 deles foram criados com população até 3.000 mil habitantes. Hoje 58,36\% dos municípios catarinenses possuem população até 10.000 mil habitantes, contra 54,08\% em 1970. Atualmente 12 municípios possuem população acima de 
100.000 mil habitantes e somente 1 acima de 500.000 mil. Em 1970 eram 4 os municípios acima de 100.000 mil habitantes e nenhum acima de 500.000 mil. Uma observação requer destaque: Lages representava 4,44\% da população catarinense em 1970 passou para 2,54\% em 2010 e Joinville passou de 4,34\% em 1970 para 8,34\% em 2010.Registra-se também que o Estado possui 36 municípios costeiros que representam $1 / 3$ da população catarinense, com uma densidade demográfica de $187 \mathrm{hab} / \mathrm{km}^{2}$, sendo que a densidade demográfica do Estado é 65,27 hab/km² (IBGE, 2011b).

Outra observação que chama a atenção é que de 2000 para 2010 cresceu de 47 para 55 o número de com população de 1 até 3.000 mil habitantes, e uma diminuição de 41 para 29 o número de municípios com população entre 5.001 até 7.000 mil habitantes, o que indica que houve uma migração da população residente, isso porque houve pouca alteração na estrutura da tabela 4.Registra-se ainda que comparando os dados do Censo $2000 \mathrm{com}$ os dados do Censo 2010, verifica-se que dos 293 municípios catarinenses em 201099 deles registram perdas populacionais. O maior crescimento se deu em Joinville, Florianópolis e Blumenau, com um aumento populacional de 85.684 mil, 78.925 mil e 47.203 mil. Já a maior perda se deu em Correia Pinto, Imaruí e Anita Garibaldi, um saldo negativo de 2.241 mil, 1.732 mil e 1.650 mil (IBGE, 2000; 2011).

Tabela 4: Número de municípios por escalonamento populacional

\begin{tabular}{|c|c|c|c|c|c|}
\hline Escalonamento & 1970 & 1980 & 1991 & 2000 & 2010 \\
\hline De 1 até $3.000 \mathrm{mil}$ & 10 & 8 & 9 & 47 & 55 \\
\hline De 3.001 até $5.000 \mathrm{mil}$ & 28 & 29 & 36 & 59 & 53 \\
\hline De 5.001 até $7.000 \mathrm{mil}$ & 28 & 24 & 23 & 41 & 29 \\
\hline De 7.001 até $10.000 \mathrm{mil}$ & 40 & 39 & 43 & 35 & 34 \\
\hline De 10.001 até $15.000 \mathrm{mil}$ & 37 & 33 & 37 & 42 & 41 \\
\hline De 15.001 até $20.000 \mathrm{mil}$ & 20 & 18 & 19 & 19 & 20 \\
\hline De 20.001 até $25.000 \mathrm{mil}$ & 13 & 15 & 10 & 11 & 13 \\
\hline De 25.001 até $30.000 \mathrm{mil}$ & 3 & 7 & 9 & 3 & 7 \\
\hline De 30.001 até $40.000 \mathrm{mil}$ & 7 & 9 & 7 & 9 & 9 \\
\hline De 40.001 até $50.000 \mathrm{mil}$ & 4 & 5 & 8 & 8 & 5 \\
\hline De 50.001 até $70.000 \mathrm{mil}$ & 2 & 1 & 6 & 6 & 12 \\
\hline De 70.0001 até $90.000 \mathrm{mil}$ & 1 & 4 & 1 & 3 & 2 \\
\hline De 90.001 até $150.000 \mathrm{mil}$ & 3 & 1 & 5 & 4 & 5 \\
\hline De 150.001 até $200.000 \mathrm{mil}$ & - & 3 & 1 & 3 & 4 \\
\hline De 200.001 até $300.000 \mathrm{mil}$ & - & 1 & 2 & 1 & 1 \\
\hline De 300.001 até $500.000 \mathrm{mil}$ & - & - & 1 & 2 & 2 \\
\hline Acima de $500.001 \mathrm{mil}$ & - & - & - & - & 1 \\
\hline TOTAL & 196 & 197 & 217 & 293 & 293 \\
\hline
\end{tabular}

Fonte: IBGE, vários anos. 
Nesta direção, em 1970 a região Oeste do Estado que representava 25,70\% da população estadual passou para $19,60 \%$ em 2010, a região Sul de $17,20 \%$ para $14,80 \%$, a região Serrana de $11,10 \%$ para $6,80 \%$, a região Norte de $14,70 \%$ para $19,40 \%$, o Vale do Itajaí de $19,90 \%$ para $23,50 \%$ e a região da grande Florianópolis de $11,30 \%$ para 15,70\%. Em resumo, as regiões Oeste, Sul e Serra perderam participação no total da população enquanto que as regiões Norte, Vale do Itajaí e grande Florianópolis aumentaram sua participação. Podemos dizer que as regiões que foram se constituindo com maior grau de complexidade industrial (produção, distribuição, consumo e trocas), que desenvolveram em ritmo mais acelerado as forças produtivas e que apresentam uma maior divisão social do trabalho passaram a concentram maior parte da população de Santa Catarina. Onde quer que se situe no território, "nunca uma cidade se apresenta sem o acompanhamento de outras cidades. Umas senhoras, outras servas ou mesmo escrava, estão ligadas, formam uma hierarquia, na Europa, na China ou em qualquer lugar" (BRAUDEL, 1995, 441).

A ampliação e melhoria dos sistemas de transportes e de comunicações permitiram maior oportunidade de acessibilidade na circulação de mercadorias e pessoas. Neste contexto, fortaleceu a integração econômica das regiões reforçando a concentração desconcentrada da indústria, serviços, produção, consumo e população. E esta tem sido uma das características marcante da história brasileira e catarinense a partir da década de 1960. Desta forma é preciso entender que as migrações não têm somente consequência para o desenvolvimento regional, mas também implicações importantes para a estrutura das desigualdades. Nessa perspectiva, é que

O movimento migratório revela o movimento de constituição das disparidades e desigualdades espaciais. E, sobre este espaço desigualmente organizado e articulado compreende a coexistência de processos espaciais, donde novos e outros tipos de fluxo migratórios se realizam. A lógica permite aceitar que a existência das desigualdades regionais permitiria assumi-las como fato principal da origem das migrações internas que acompanham a industrialização nos moldes capitalistas (MENEZES, 2000, p. 3).

Quanto aos fluxos migratórios, entre 1995 e 2000, 199.653 pessoas escolheram o Estado como endereço, enquanto outras 139.667 saíram de Santa Catarina. O saldo positivo de 59.986 moradores a mais deixou Santa Catarina como o terceiro mais procurado, atrás apenas de São Paulo (339,9 mil) e Goiás (202,8 mil). Os dados do período 2005 e 2010 revelam um dado ainda maior: o crescimento de 59,00\% no total de pessoas que saíram de seus Estados para morar em Santa Catarina elevou para 174.112 a mais o quadro populacional do Estado. A Capital foi à cidade catarinense que recebeu mais migrantes de Rondônia, Amazonas, Pará, Alagoas, Bahia, Minas Gerais, Rio de Janeiro, São Paulo, Rio Grande do 
Sul, Mato Grosso do Sul, Goiás e Distrito Federal. O maior número de migrações veio do Rio Grande do Sul (16.439 pessoas), seguido pelo Paraná (6.930 pessoas) e São Paulo (6.176 pessoas) (IBGE, 2011). Nesse contexto, o PNAD (2011) revelou que mais de 40,10\% da população do Brasil é migrante. De uma população de 195,2 milhões de pessoas, 78,2 milhões $(40,10 \%)$ não mora na cidade onde nasceu contra 117 milhões $(59,90 \%)$ naturais do município.

Entre 2000 e 2010 Santa Catarina foi o Estado que recebeu o maior volume de migrantes de outros Estados e imigrantes de outros países segundo dados da Amostra do Censo Demográfico 2010. No Brasil, de 2000 a 201011.316 .720 pessoas trocaram de Estado, contra 9.909.119 na década anterior. Destaque que no período 2000-2010 638.494 mil $(5,60 \%)$ migraram para Santa Catarina. Com uma população de 6.248.436 habitantes, 5.130.746 são naturais de Santa Catarina enquanto que 1.117.690 nasceram em outro Estado, ou mesmo no exterior. Motivado por inúmeros motivos, a última amostragem do Censo registrou que Santa Catarina recebeu 638.494 pessoas de outras regiões do país e do exterior (IBGE, 2011; 2011b).

\begin{abstract}
A sociedade brasileira se urbaniza e na década de sessenta a população urbana supera a rural. As maciças migrações internas transitam pelo mercado de trabalho nacionalmente integrado acelerando, ao mesmo tempo, o processo de urbanização e metropolização. Esse novo perfil da sociedade brasileira, urbana, metropolitana e industrial, tem a marca estrutural das migrações internas que, simultaneamente, colaboraram para a constituição de uma sociedade nacionalmente integrada, mas com fortes desequilíbrios regionais e sociais (BRITO et al, 2012, p. 7).
\end{abstract}

Em Balneário Camboriú 79,23\% dos moradores não nasceram no município, isso quer dizer, são migrantes. Em Florianópolis apesar da metade da população não ter nascido na cidade, os números derrubam um mito, o "manezinho" não é raridade ele representa 48,29\% das pessoas que vivem na Capital. O município mais catarinense do Estado é Atalanta. Situada no Vale do Itajaí, colonizado por italianos e alemães, lá moram 3.300 habitantes, 99,43\% deles nasceram no Estado. Depois vem Agronômica (99,26\%) e Bela Vista do Toldo (99,23\%). Formosa do Sul, no Oeste, é a cidade das raízes. Em Formosa do Sul 90,92\% dos moradores moram no município há mais de 10 anos. Ao contrário de Vidal Ramos, no Vale do Itajaí, onde 67,86\% estão na cidade há menos de um ano (IBGE, 2011).

Em pesquisa realizada pelo IBGE divulgada em 2013 na recontagem da população brasileira mostrou que no Estado de Santa Catarina a cidade mais procurada pelos migrantes foi Araquari, no Norte do Estado. A recontagem do IBGE mostrou que Araquari é o município de Santa Catarina com maior aumento nos últimos dois anos. O crescimento 
chegou a 10,00\%. Com 26 mil habitantes, as instalações de indústrias metalúrgicas são as grandes responsáveis por esse crescimento. A estimativa é que as migrações para a cidade cresçam ainda mais com a instalação da unidade da empresa alemã BMW. Expectativas da Associação Empresarial e Agrícola de Araquari (ACIAA) é que como resultado das migrações a população aumente em 50\% nos próximos 10 anos (DIÁRIO CATARINENSE, 2012).

Como aponta o trabalho de Baeninger (2012) em que o século XXI anuncia a expansão dos espaços da migração no Brasil que serão demarcados pelo crescimento das áreas de rotatividade migratória, embora que as migrações interestaduais continuem apresentando decréscimos em seus volumes. Porém segundo estudo de Baeninger (2012, p. 83) esse decréscimo "[...] não implica em uma tendência de estagnação das migrações; ao contrário, denota outros arranjos da própria migração interna, bem como seus atuais desdobramentos, com novas modalidades de deslocamentos populacionais em âmbitos locais e regionais".

Dentro do movimento migratório interestadual, de todos os migrantes brasileiros com destino a Santa Catarina, a maioria veio da Região Sul (67,81\%). Neste período de dez anos, o Estado recebeu mais migrações do Paraná (40,00\%) e do Rio Grande do Sul (30,00\%). Dos 638.494 mil migrantes que Santa Catarina recebeu entre 2000 e 2010, 212.702 vieram do Paraná, seguidos dos gaúchos 162.422. No período, Santa Catarina recebeu 20.872 imigrantes estrangeiros. A maior parcela ficou para os Estados Unidos, com 4.418, seguidos do Paraguai, 2.630 e Argentina, 1.984. Enquanto que no período de 1995 a 2000, movimentaram-se 30,6 migrantes para cada mil habitantes, valor que caiu para 26,3 migrantes para cada grupo de mil entre 2005 e 2010 (IBGE, 2011).

No que compete aos fluxos migratórios, até os fins da década de 1970 o movimento migratório era uma marcha pela esperança de uma vida melhor. Já após 1980 era uma forma de marcha pela sobrevivência (CANO, 2008). Usando das palavras de Menezes (2000, p. 4) "A migração seria vista como uma estratégia para as pessoas maximizarem o seu acesso às oportunidades irregularmente repartidas no espaço e desigualmente disponíveis no tempo". Na interpretação de Brito et al. (2012, p. 6),

A mobilidade espacial da população, em especial, a migração interna, é um fenômeno estrutural e, como tal, não se apreende as suas grandes transformações a não ser do ponto de vista histórico. No Brasil, em particular, as migrações internas se constituíram em um dos determinantes estruturais mais importantes da formação das suas sociedade e economia contemporâneas. Não seria equivocado afirmar que as migrações acompanharam a nossa história desde o período colonial, passando pelo Império e chegando à República. 
No tocante da acumulação da riqueza estadual e da concentração demográfica, ambas acompanham a concentração dos meios de produção, distribuição de mercadorias, relações de troca e consumo, onde cada qual aparece como meio do outro, é mediado pelo outro e expressos como dependência recíproca. Em todos os casos, as cidades enquanto "transformadores elétricos" (BRAUDEL, 1995) produzem uma interação entre os diferentes momentos e que a produção, distribuição, troca e consumo são membro de uma totalidade, diferentes dentro de uma unidade (MARX, 2011).

Com base nos dados do PIB municipal, enquanto que em 1999 os dez municípios mais ricos concentravam 46,90\% do PIB estadual, em 2010 passaram a concentrar 50,60\%. Destaque para o crescimento de $897 \%$ no PIB de Itajaí (586\% acima do crescimento estadual no período), crescimento este sustentado pelo programa de incentivo fiscal Pró-Emprego criado em 2007 que reduziu a alíquota de ICMS de 17,00\% para 3,00\% no ato do desembaraço aduaneiro. Exemplo é que das 817 empresas beneficiadas pelo enquadramento do programa entre 2007 e 2011119 delas se instalaram em Itajaí, 88 em Joinville, 46 em Blumenau e 42 em Florianópolis, o que significa uma representação de 40,51\% (GOULARTI, 2014).

Decorrente dos incentivos fiscais que favoreceram Itajaí, isso fez com que diversas empresas transferissem o seu faturamento para lá. Muitas empresas que antes realizavam a apuração do imposto em municípios da região Oeste do Estado passaram a realizar em Itajaí. As transformações das exportações e importações da economia catarinense pós-2007 vem alterando a configuração urbano-regional no Estado, reforçando especializações regionais. Ademais, as melhores condições de infraestrutura e da logística da região portuária e do Litoral catarinense acabam contribuindo na reestruturação do território, por consequência aumentando a migração interna para a região portuária e litorânea.

Dentro da reestruturação da administração pública, com as Secretaria de Desenvolvimento Regional pretendia-se "[...] combater a litoralização, que vem esvaziando, dramaticamente, o campo, e inchando, deformando as cidades, a começar por nossa bela Capital" (SILVEIRA; MOREIRA, 2002, p. 1). Mas o que vimos (Mapa 1) é que de 2000 a 2010 das dez cidades que mais cresceram, sete ficam no Litoral. Não diferente do Censo de 2000 que das dez cidades catarinenses em que a população mais cresceu (entre 1991 a 2000) oito estão no Litoral. O Censo mostra ainda que os municípios que mais perderam população situam-se na região do grande Oeste (IBGE, 1991; 2011). 
O processo de migração das populações não se constituiu uma novidade histórica. Os países capitalistas de primeira geração (Inglaterra) e os de segunda geração (Europeus, Estados Unidos e Japão) apresentaram todos a mesma tendência, ou seja, uma maciça transferência da população que reside nas zonas rurais para as cidades. Mas a questão que levantamos é que os dados apresentados no Censo 2010 mostram que os objetivos pretendidos com a criação das 29 Secretarias de Desenvolvimento Regional (SDR) em 2003 (atualmente são 36) não foram logrados, ou melhor, não se estancou o processo de urbanização e muito menos de litoralização (GOULARTI, 2014b).

Ao mesmo tempo em que concentram a maior parte da população estadual, as regiões de Joinville, Blumenau e Florianópolis concentram 55,70\% do número total de empregos formais do Estado, 55,60\% do Valor Adicionado Bruto (VAB) da indústria, 60,40\% do VAB do setor de serviços, 9,20\% do VAB agropecuário, 49,10\% do consumo industrial de energia elétrica, sendo somente o município de Joinville representa 22,50\% e 67,10\% do consumo comercial de energia elétrica (SANTA CATARINA, 2013). Outra observação é que o crescimento da rede urbana está relacionado com a perda da participação do setor primário na composição do PIB estadual - que compunha 48,10\% em 1950 passa para 38,30\% em 1970 depois para 23,10\% em 1990 e 8,20\% em 2010.

Compreender as relações que se estabelecem a partir das novas determinações sobre os processos de urbanização em Santa Catarina, bem com o impacto sobre a rede urbana brasileira é uma tarefa que precisa ser aprofundada, especialmente dentre as figuras públicas. Lefebvre $(2008$, p. 49) ao pesquisar sobre a "revolução urbana" coloca que "atualmente o fenômeno urbano surpreende por sua enormidade; sua complexidade ultrapassa os meios do conhecimento e os instrumentos da ação prática". Contudo, para tamanha complexidade gerada pelo processo de urbanização, Maricato (2000, p. 169) defende em sua pesquisa que para a "construção da nova matriz urbanística passa pela eliminação da distância entre planejamento urbano e gestão".

Embora as transformações - o "fenômeno urbano", a "revolução urbana" (LEFEBVRE, 2008), a “arrebentação urbana” e "urbanização suportável” (CANO, 2011) em Santa Catarina atravessa sejam de menores proporções que Rio de Janeiro (Capital), São Paulo (Capital), Distrito Federal (Brasília), Ceará (Fortaleza), Bahia (Salvador), Minas Gerais (Belo Horizonte), Rio Grande do Sul (Porto Alegre) e demais Estados brasileiros, o caos urbano explodiu e seguramente veio para ficar. Embora o Censo 2010 tenha demonstrado que a taxa de fecundidade, a taxa de urbanização e a migração tenham diminuído a tendência de 
crescimento em relação às décadas anteriores, a sociedade urbana contemporânea imprime com maior força e com maior intensidade as contradições da sociedade capitalista.

\section{MAPA DA VIOLÊNCIA E URBANIZAÇÃO}

Com o processo de concentração e centralização da riqueza em poucas cidades, as migrações são uma consequência. Todavia o resultado tem sido o aumento considerável da criminalização e da violência urbana.

A urbanização acelerada gerou uma série de efeitos complexos que superdimensionaram vários problemas de ordem municipal, multiplicando seus tamanhos e custos, tornando-os, assim, problemas regionais, estaduais ou mesmo federal. Esse efeito estimulou o aumento da especulação imobiliária, encareceu sobremodo os custos da infraestrutura urbana e piorou a qualidade de vida urbana. Além disso, o elevado encarecimento da moradia e a omissão e corrupção política dos órgãos públicos amplificou também a ocupação de espaços impróprios para assentamentos humanos, como morros, encostas, alagadiços e outros. Desta forma, do ponto de vista social, a exclusão tornou-se menos rural e mais urbana, onde se combina a concentração da riqueza com a exclusão social e a marginalidade (DINIZ, 2005).

Segundo levantamento do Mapa da Violência, que permitem uma visão panorâmica e simultaneamente da violência homicida no país, traz um conjunto de preocupação que requer uma melhor interpretação e compreensão do problema da violência urbana. A média de homicídios em 2012 é maior do que o registrado nos anos anteriores - em 2011 (2,2), 2010 (2,4), $2009(2,2)$ e $2008(2,1)$ mortes por dia. O Mapa da Violência mostra que nas regiões com maior conurbação urbana o número de homicídios e maior. Oito das 10 cidades mais populosas estão no Litoral. É justamente no Litoral que os homicídios mais acontecem. Joinville e Florianópolis, que têm o maior número de habitantes, estão também empatadas no topo do ranking dos homicídios no Estado. Ademais, o Mapa da Violência nos mostra que uma pessoa é assassinada a cada oito horas em Santa Catarina (WAISELFISZ, 2014).

Tabela 5: Homicídios em Santa Catarina (2008-2012)

\begin{tabular}{l|r|r|r|r|r}
\hline \multirow{2}{*}{ Município } & \multicolumn{6}{|c}{ Número de Homicídios } \\
\cline { 2 - 6 } & $\mathbf{2 0 0 8}$ & $\mathbf{2 0 0 9}$ & $\mathbf{2 0 1 0}$ & $\mathbf{2 0 1 1}$ & $\mathbf{2 0 1 2}$ \\
\hline Joinville & 86 & 89 & 83 & 76 & 86 \\
\hline Florianópolis & 91 & 84 & 97 & 87 & 65 \\
\hline Criciúma & 22 & 23 & 28 & 31 & 55 \\
\hline
\end{tabular}




\begin{tabular}{l|r|r|r|r|r} 
Chapecó & 47 & 35 & 42 & 62 & 46 \\
\hline São José & 38 & 51 & 43 & 53 & 41 \\
\hline Itajaí & 63 & 71 & 57 & 57 & 38 \\
\hline Camboriú & 10 & 27 & 17 & 22 & 32 \\
\hline Blumenau & 30 & 25 & 32 & 27 & 28 \\
\hline Palhoça & 20 & 12 & 12 & 14 & 22 \\
\hline Lages & 14 & 14 & 26 & 22 & 20 \\
\hline Jaraguá do Sul & 11 & 6 & 12 & 18 & 19 \\
\hline Balneário Camboriú & 28 & 25 & 30 & 17 & 18 \\
\hline Total & $\mathbf{4 6 0}$ & $\mathbf{4 6 2}$ & $\mathbf{4 7 9}$ & $\mathbf{4 8 6}$ & $\mathbf{4 7 0}$ \\
\hline Total Santa Catarina & $\mathbf{7 8 9}$ & $\mathbf{8 0 0}$ & $\mathbf{8 1 2}$ & $\mathbf{7 9 7}$ & $\mathbf{8 1 6}$ \\
\hline
\end{tabular}

Fonte: WAISELFISZ, 2014 - Mapa da Violência.

Embora a taxa média de homicídio em Santa Catarina seja a menor do Brasil, de 2000 para 2012 houve um crescimento de 7,90\% para 12,80\%. Esse crescimento é pequeno quando comparado com Alagoas, que passou de 25,60\% para 66,80\%, Pará, de 13,00\% para 45,90\%, Ceará, de 16,00\% para 29,70\%, Maranhão, de 6,10\% para 22,50\% e Paraíba, de 15,10\% para $38,60 \%$. No contexto nacional, os Estados mais pobres são aqueles que apresentam a maior taxa de homicídios, enquanto que Estados como São Paulo e Rio de Janeiro registram queda, $42,20 \%$ para $13,90 \%$ e $51,00 \%$ para $26,20 \%$. No geral a taxa de homicídios cresceu no Brasil, atingindo, em 2012, o maior índice de que se tem registro desde 1980, ou seja, passou de 49.695 em 2002 para 56.337 em 2012 (WAISELFISZ, 2014).

No Estado, no topo do ranking aparece o município de Joinville, a cidade mais populosa do Estado como também a que apresenta um elevado grau de complexidade industrial. Das 12 cidades mais violentas, duas observações a serem relacionadas: são estes os municípios mais populosos do Estado como também os que detêm maior participação no PIB estadual. Na média, os municípios relacionados na tabela acima representam $58,60 \%$ dos homicídios e 42,20\% da população estadual. Cidades como Navegantes, Araquari e São Francisco do Sul que não estão nominadas também apresentam taxa de homicídios acima da média estadual.

Quando retratado por região, a maior incidência em homicídios localiza-se na Região Metropolitana (RM) da Foz do Rio Itajaí, seguido da RM de Florianópolis e RM do Norte/Nordeste. Por último, ao abrirmos ainda mais os dados do Mapa da Violência, verificase que a taxa de homicídio nos municípios com população entre 2 mil e 10 mil habitantes praticamente não existe. As maiores incidências de homicídios estão concentradas nas cidades acima de 20 mil habitantes (WAISELFISZ, 2014). 
Tabela 6: Taxa de homicídio (100 mil habitantes) por tamanho de município (2000-2010)

\begin{tabular}{|c|c|c|c|c|c|c|}
\hline \multirow[b]{2}{*}{ Tamanho do Município } & \multicolumn{2}{|c|}{ Homicídios 2000} & \multicolumn{2}{|c|}{ Homicídios 2010} & \multirow[b]{2}{*}{$\Delta \%$ Taxas } & \multirow[b]{2}{*}{$\mathbf{N}^{\circ}$ Municípios } \\
\hline & $\mathbf{N}^{\mathbf{o}}$ & Taxa & $\mathbf{N}^{\mathbf{o}}$ & Taxa & & \\
\hline Até 5 mil habitantes & 25 & 7,2 & 16 & 4,7 & $-34,72$ & 108 \\
\hline De 5 a 10 mil & 34 & 7,7 & 40 & 8,6 & 11,69 & 64 \\
\hline De 10 a 20 mil & 46 & 6,4 & 51 & 6,2 & $-3,13$ & 60 \\
\hline De 20 a 50 mil & 60 & 7 & 105 & 10,4 & 48,57 & 34 \\
\hline De 50 a $100 \mathrm{mil}$ & 61 & 7,6 & 160 & 13,8 & 81,58 & 15 \\
\hline De 100 a 200 mil & 89 & 9,1 & 209 & 17,3 & 90,11 & 8 \\
\hline De 200 a 500 mil & 65 & 8 & 171 & 18,2 & 127,50 & 3 \\
\hline Acima de 500 mil & 46 & 10,7 & 83 & 16,1 & 50,47 & 1 \\
\hline
\end{tabular}

Fonte: WAISELFISZ, 2014 - Mapa da Violência.

As áreas mais violentas de Santa Catarina são justamente as cidades mais populosas e onde se concentram a maior parte da produção, da distribuição, do consumo estadual e das trocas mercantis. Enquanto que a taxa de homicídios diminuiu 34,72\% nos municípios de até 5 mil habitantes, cresceu $81,58 \%, 90,11 \%$ e 127,50\% nos municípios de 50 a 100 mil, 100 a 200 mil e 200 a 500 mil. Isso mostra que os municípios que receberam migrantes e imigrantes são aqueles que apresentam maior índice de violência e aqueles que perderam população residente são os que sequer aparecem nas estatísticas de homicídios (WAISELFISZ, 2014).

Abrindo os dados da violência urbana em Santa Catarina é possível observar que a incidência de crimes está na faixa etária entre 25 e 35 anos onde o motivo principal da ocorrência é o "não esclarecido", seguido pelo tráfico. Outro ponto a ser observado é o local do crime. As áreas mais violentas nas cidades de Joinville, Florianópolis, Criciúma, Chapecó, São José e Itajaí como nas demais, são áreas onde concentram uma população com menor renda salarial, baixa escolaridade, emprego precário e piores condições de moradia urbana. $\mathrm{O}$ Mapa da Violência 2014 revela ainda que enquanto a taxa de homicídio na população branca é $12,20 \%$, na população negra é $17,00 \%$, sendo que a taxa de homicídio na população negra jovem é 33,10\% e na branca 22,10\% (WAISELFISZ, 2014).

Por último, dados publicados em 2011 pela Secretaria de Estado da Segurança de Santa Catarina apontaram que 151 municípios catarinenses não registraram ocorrência dolosa que resultaram em morte, em 2012 foram 150 e em 2013 foram 142 cidades. As tipificações consideradas para este levantamento não são apenas de homicídios, mas também de latrocínio, confronto com a polícia que resulta em morte, lesão corporal seguida de morte e infanticídio. Em 2014 (até junho) 194 cidades que não registraram homicídios, o equivalente a 65,76\% dos municípios catarinenses (SANTA CATARINA, 2014). 


\section{CONSIDERAÇÕES FINAIS}

As cidades rompem um conjunto de relações sociais (trabalho e poder) e passam a tencionar as relações mercantis (produção e troca), produzindo assim uma divisão do trabalho entre urbano e rural. É a partir da transformação da cidade em centro de produção que se funda divisão do trabalho, ou seja, essa divisão ocorre somente depois que a cidade já existe. $\mathrm{Na}$ medida em que as cidades começam a atrair pessoas e se tornar urbana em detrimento do seu desenvolvimento acirram-se os contrates entre campo e cidade. Como imãs, as cidades passam a atrair todo o tipo de pessoas (pobres e ricos). Tratando-se de um processo inevitável, o resultado disso é o crescimento desordenado que tem como resultado numa enormidade de problemas - violência, conurbação, mobilidade.

Analisando o processo de migração em Santa Catarina, é possível perceber que nas últimas décadas os Estado têm recebido mais migrantes do que expulsado e que a população residente do Planalto Serrano e do Grande Oeste está migrando para o Litoral. Embora se registre um declínio na taxa de fecundidade nas últimas décadas, a urbanização e a litoralização mantiveram-se em ritmo acelerado agravando a crise social aumentando os índices de violência e produzindo uma deterioração do padrão de vida onde até final dos anos 1990 parte considerável dos migrantes rurais passou a engrossar as camadas da economia informal das cidades, mulheres nos serviços domésticos e homens na construção civil.

Embora Santa Catarina possua um pouco mais de 6 milhões de habitantes, uma cidade acima de 500.001 mil, duas entre 300.001 e 500.000 mil e uma entre 200.001 e 300.000 mil habitantes e não possua um grande centro urbano a exemplo das metrópoles brasileiras, cidades como Florianópolis, Joinville, Blumenau seguido de Criciúma, Chapecó e Itajaí apresentam características semelhantes a problemática das grandes cidades brasileiras. Com a especulação imobiliária segrega à medida que reservam os melhores terrenos da cidade a população mais rica, os migrantes pobres de outros Estados e do próprio Estado foram morar nos morros, encostas de morros, beira de rios e áreas de risco transformando a problemática urbana em problemática social. Para tanto, a ausência do setor público na formulação do planejamento especificamente urbano é parte importante da política de planejamento privado da especulação imobiliária. O Estado ao relegar o planejamento especificamente urbano o entrega a iniciativa privada.

Com processo de urbanização e crescimento desordenado das cidades litorâneas, em 2003 o governo catarinense cria 29 Secretarias de Desenvolvimento Regional com objetivo de 
frear a litoralização. Hoje são 36 Secretarias Regionais e o processo de migração das regiões da Serra Geral e do grande Oeste rumo ao Litoral continuou conforme dados apresentados pelo Censo 2010. Registra também que na última década houve um processo de centralização e concentração da riqueza. As dez cidades com a maior participação no PIB em 2000 aumentaram sua concentração, passando de 46,90\% para 50,60\% em 2010. São justamente as cidades que apresentam maior grau de complexidade na divisão social do trabalho as mais violentas.

Ao longo dos últimos 70 anos, podemos dizer que não foi por falta de planejamento, planos e legislações urbanísticas que as cidades catarinenses cresceram e estão crescendo de forma desordenada. Nos anos que sucede 1960 a 2010, foram criados diversos Planos Territoriais com foco no planejamento e no desenvolvimento. Entre eles incluem-se a Política de Desenvolvimento Regional e Urbano para Santa Catarina, Plano Básico de Desenvolvimento Ecológico-Econômico, Atlas de Santa Catarina, Santa Catarina, Estado onde investir, Plano Básico de Desenvolvimento Regional, Zoneamento Ecológico Econômico, Programa Integrado de Desenvolvimento Socioeconômico, Plano de Gerenciamento Costeiro. São planos buscaram o diálogo e a organização dos sujeitos à escala regional. Poderíamos acrescentar a criação das36 Secretarias de Desenvolvimento Regional, as 21 Associações de Municípios, as seis Mesorregiões, as 20 Microrregiões geográficas definidas pelo IBGE, os 16 Comitês de Bacias Hidrográficas, os 16 Fóruns de Desenvolvimento Regional e as onze Regiões Metropolitanas. A questão é o descolamento destes sucessivos planos ao planejamento especificamente urbano.

Nas últimas décadas a análise dos resultados apresentados permite afirmar que Santa Catarina vem vivenciando um amplo processo de transformação, no que se refere a sua distribuição populacional. Uma dessas transformações é que enquanto que os municípios litorâneos receberam migrantes e apresentaram crescimento populacional acima da média estadual, os municípios do Planalto Serrano e do Oeste catarinense nas últimas décadas sofreram uma redução populacional ou apresentaram saldos migratórios negativos, ou seja, estão vivenciando um processo de desruralização.

A despeito da velocidade do processo de urbanização nas regiões mais industrializadas, há que entendê-lo como de uma "urbanização suportável" (CANO, 2011), dada a existência de mecanismos de assentamento e acomodação das camadas de baixa renda, em termos de possibilidade de uma periferização ainda próxima aos centros urbanos, acesso a lotes baratos ou ocupação de áreas de risco, como morros, alagados e outras áreas ruins ou 
inapropriadas. $\mathrm{O}$ avanço da urbanização, da especialização regional e da inserção externa da economia catarinense no mercado internacional fará com que a questão urbana e a política habitacional passem a ser vistas com outro olhar. Daí hoje o grande desafio para o Estado de Santa Catarina e dos governos municipais, e também do governo federal, é a administração dessas aglomerações urbanas como também a explosão da violência urbana nas últimas décadas.

O não enfrentamento do setor público se deve, assim compreendemos, dentro de um planejamento especificamente urbano que tenha como baliza a justiça social para o conjunto da coletividade significa uma "traição do Estado". A questão é tencionar os que produzem o espaço urbano (os proprietários dos meios de produção, sobretudo os grandes industriais; os proprietários fundiários; os promotores imobiliários; o Estado; e os grupos sociais excluídos) para a construção de uma cidade e um espaço urbano com condições dignas de moradia, de sobrevivência e de qualidade de vida. No caso da introdução permanente de inovação tecnológica, causa direta da desaceleração do emprego, é difícil prever o contrário da deterioração do padrão de vida urbana e rural.

Estamos certos que a sociedade está perplexa e apavorada diante do caos urbano. Todavia a questão é saber se a sociedade urbana que está cada vez mais num processo de segregação e conurbação saberá evitar o aumento desenfreado da violência, da criminalização, da segregação social e da deterioração do padrão de vida.

\section{REFERÊNCIAS}

BAENINGER, R. Rotatividade Migratória: um novo olhar para as migrações internas no Brasil. Ver. Inter. Mob. Hum., Brasília, Ano XX, No 39, p 77-100, jul./dez. 2012.

BRITO, F. [et. al] A mobilidade interestadual da população no Brasil no início do século XXI : mudança no padrão migratório. Belo Horizonte (MG) : UFMG/CEDEPLAR. 26 p. : il. - (Texto para discussão, 465), 2012.

BRAUDEL, F. Civilização material, economia e capitalismo, séculos XV-XVIII. [Volume 1 - “As estruturas do cotidiano"]. SP: Martins Fontes, Cap. 8 “As cidades”, pág.439-510, 1995.

CANO, W. Desconcentração produtiva regional do Brasil 1970-2005. São Paulo (SP): Ed. UNESP., 2008. 294p.

CANO, W. Ensaios sobre a crise urbana do Brasil. Campinas (SP): Ed. Unicamp., 2011. $373 p$. 
CANO, W.Novas determinações sobre as questões regional e urbana após 1980. Revista Brasileira de Estudos Urbanos e Regionais, Local de publicação, 13, junho., 2012.

CARDOSO DE MELLO, J. M. O capitalismo tardio: contribuição à revisão crítica da formação e do desenvolvimento da economia brasileira. 9. ed. $1^{\text {a }}$ reimp. São Paulo (SP) : Editora Brasiliense. 1998. 182p.

DIÁRIO CATARINENSE. Entrevista: Raimundo Colombo, Governador. Florianópolis (SC) : 23/10/2012. Disponível em: <http://www.sef.sc.gov.br/clipping/23102012>. Acesso em: 21 de junho de 2015.

DINIZ, C. Território e Nação. In: IPEA. Brasil: o Estado de uma Nação. Brasília, IPEA, p. 158-197., 2005.

GOULARTI, J. G. Desenvolvimento Desigual: incentivos fiscais e acumulação em Santa Catarina. Florianópolis (SC): Ed. Insular, 2014. 192p.

GOULARTI, J. G. Um decênio das secretarias de desenvolvimento regional em S.

Catarina: o que mudou? VIII Encontro de Economia Catarinense. Data: 08 e 09de maio de 2014. UNIDAVI, Rio do Sul - SC Área Temática: Economia regional e urbana., 2014b

INSTITUTO BRASILEIRODE GEOGRAFIA EESTATÍSTICA - IBGE Censo

Demográfico 1991: famílias e domicílios. Resultados das amostras. Rio de Janeiro (RJ): IBGE, nº 22, p.1-232., 1991.

IBGE. Censo Demográfico 2000: Características da população. Resultados da Amostra. Rio de Janeiro (RJ): IBGE, p.1-178., 2000.

IBGE. Censo Demográfico 2010: Características da população e dos domicílios. Resultados do universo. Rio de Janeiro (RJ): IBGE, 270p., 2011.

IBGE. Pesquisa Nacional por Amostra de Domicílios (PNAD). Rio de Janeiro (RJ): IBGE, v. 31, p.1-135., 2011b.

LEFEBVRE, H. A revolução urbana - Tradução de Sérgio Martins - Belo Horizonte (MG): Ed. UFMG, 2008. 176p.

MARICATO, E. As ideias fora do lugar e o lugar fora das ideias: planejamento urbano no Brasil. In: ARANTES, O., VAINER, C. \& MARICATO, E. A cidade do pensamento único: desmanchando consensos. Petrópolis (RJ) : Vozes, p. 121-192., 2000.

MARX, K. Grundrisse: manuscritos econômicos de 1857-1858 : esboço da crítica da economia política. São Paulo (SP) : Ed. Boitempo. 2011. 788p.

MENEZES, M. L. P. Tendências atuais das migrações internas no Brasil. Revista Electrónica de Geografia y Ciencias Sociales. Universidad de Barcelona. No 69 (45), ago. 2000.

SANTA CATARINA. Cadernos de indicadores: Santa Catarina e suas regiões. Florianópolis (SC): Diretoria de Planejamento Orçamentário., 2013. 189p. 
SANTA CATARINA. SC é o Estado com menor taxa de homicídios a cada 100 mil

habitantes. 2014. Disponível em: < http://www.sc.gov.br/mais-sobre-seguranca-publica/sc-eoestado-com-menor-taxa-de-homicidios-a-cada-100-mil-habitantes $>$ Acesso em 24 de julho de 2015.

SILVEIRA, L. H. MOREIRA, E. P. Plano 15: por toda Santa Catarina. Florianópolis (SC) : Plano de Governo 2003-2006., 2002.

WAISELFISZ, J. J. Mapa da Violência: os jovens do Brasil. Secretaria Geral da Presidência da República; Secretaria Nacional de Juventude; Secretaria de Políticas de Promoção da Igualdade Racial. Brasília (DF): 2014. 189p. 